\title{
Erratum
}

\section{Reactions of Unsaturated Azides; Part 27: Synthesis of 1,4-Diazidobuta-1,3-dienes}

Klaus Banert,* Frank Köhler, Antje Melzer, Ingolf Scharf, Gerd Rheinwald, Tobias Rüffer, Heinrich Lang Synthesis 2011, 1561.

In Scheme 1, two extra $\mathrm{H}$ atoms appeared on the general structure for bi-2H-azirin-2-yls 2 . The correct scheme is shown here.
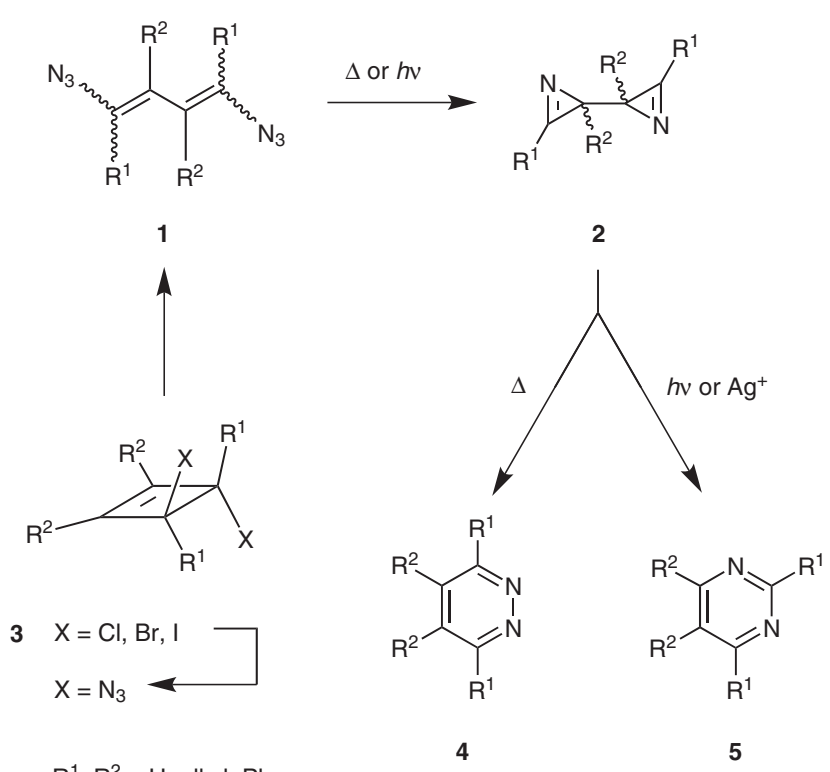

$\mathrm{R}^{1}, \mathrm{R}^{2}=\mathrm{H}$, alkyl, $\mathrm{Ph}$

Scheme 1 The only known synthesis of 1,4-diazidobuta-1,3-dienes and some of their reactions 